\title{
HUBUNGAN PENGETAHUAN DAN TINDAKAN TERHADAP DETEKSI DINI KANKER PAYUDARA PADA REMAJA PUTRI DI SMAN 10 PEKANBARU
}

\author{
Wahyuni, Rika Sri \\ Prodi DIII Kebidanan STIKes Payung Negeri \\ *Korespondensi: rikasriwahyuni1303@gmail.com
}

\begin{abstract}
Background: Breast cancer is one type of cancer with the highest percentage among other cancers. The number of breast cancer in adolescents aged 15-24 years as many as 16 people was recorded in the records of the Riau Provincial Health Office in 2015. The results of medical research at the Johns Hopkins Research Center in America stated that $40 \%$ of cancer patients who were detected early through regular home self-examinations were successful. healed. Purpose: This study aims to determine the relationship between knowledge and action on early detection of breast cancer. Methods: This research is quantitative with an analytical design that uses primary data. The research sample was 84 young women using the Proportionate Stratified Random Sampling technique. Data for knowledge and action for early detection of breast cancer were obtained by using a questionnaire and analyzed by univariate and bivariate using chi square test with SPSS. Results: The results of the univariate analysis were $50(60 \%)$ young women with sufficient knowledge, and $69(82 \%)$ young women did not do early detection of breast cancer. The results of the chi square test show that there is no relationship between knowledge and action on early detection of breast cancer. Conclusion: 15 female students who take action for early detection of breast cancer and there is no relationship between the level of knowledge of young women with early detection of breast cancer.
\end{abstract}

Keywords: Knowledge; Action; Early detection of breast cancer

\begin{abstract}
ABSTRAK
Latar Belakang: Kanker payudara merupakan salah satu jenis kanker dengan persentase tertinggi diantara penyakit kanker lainnya. Jumlah kanker payudara pada remaja berusia 15-24 tahun sebanyak 16 orang tercatat dalam catatan Dinas Kesehatan Provinsi Riau Tahun 2015. Hasil penelitian medis John Hopkins Research Centre di Amerika menyebutkan bahwa $40 \%$ penderita kanker yang terdeteksi sejak dini melalui pemeriksaan sendiri di rumah secara teratur berhasil sembuh. Tujuan: Penelitian ini bertujuan untuk mengetahui hubungan pengetahuan dengan tindakan terhadap deteksi dini kanker payudara. Metode: Penelitian ini bersifat kuantitatif dengan desain analitik yang menggunakan data primer. Sampel penelitian sebanyak 84 orang remaja putri dengan menggunakan teknik Proportionate Stratified Random Sampling. Data untuk pengetahuan dan tindakan deteksi dini kanker payudara diperoleh dengan menggunakan kuisioner
\end{abstract}


dan dianalisis secara univariat dan bivariat menggunakan uji chi square dengan SPSS. Hasil: Hasil analisis univariat terdapat 50 orang $(60 \%)$ remaja putri dengan pengetahuan cukup, serta 69 orang $(82 \%)$ remaja putri tidak melakukan deteksi dini kanker payudara. Hasil uji chi square menunjukkan tidak ada hubungan antara pengetahuan dengan tindakan terhadap deteksi dini kanker payudara. Simpulan: 15 orang siswi yang melakukan tindakan deteksi dini kanker payudara dan tidak ada hubungan antara tingkat pengetahuan remaja putri dengan tindakan deteksi dini kanker payudara.

Kata Kunci : Pengetahuan; Tindakan; Deteksi dini kanker payudara

\section{PENDAHULUAN}

Penyakit kanker adalah penyakit yang timbul akibat pertumbuhan tidak normal sel jaringan tubuh yang berubah menjadi sel kanker, sedangkan tumor adalah kondisi di mana pertumbuhan sel tidak normal sehingga membentuk suatu lesi atau dalam banyak kasus benjolan tubuh (Savitri, 2015).

Berdasarkan data GLOBOCAN, Internasional Agency for Research on Cancer (IARC), diketahui bahwa pada tahun 2012 terdapat 14.067.894 kasus baru kanker dan 8.201.575 kematian akibat kanker di seluruh dunia. Kanker payudara, kanker prostat, dan kanker paru merupakan jenis kanker dengan persentase kasus baru (setelah di kontrol dengan umur) tertinggi, yaitu sebesar 43,3\%, 30,7\%, dan $23,1 \%$. Sementara itu, kanker paru dan kanker payudara merupakan penyebab kematian (setelah di kontrol dengan umur) tertinggi akibat kanker (Primadi, 2016)

Kanker payudara merupakan keganasan yang berasal dari kelenjar, saluran kelenjar, dan jaringan penunjang tidak termasuk kulit payudara. Sel kanker payudara yang pertama dapat tumbuh menjadi tumor sebesar $1 \mathrm{~cm}$ dalam waktu 812 tahun. Sel kanker tersebut diam pada kelenjar payudara. Sel-sel kanker payudara ini dapat menyebar melalui aliran darah ke seluruh tubuh. Sel kanker payudara dapat bersembunyi di dalam tubuh kita selama bertahun-tahun tanpa kita ketahui dan tiba-tiba aktif menjadi tumor ganas atau kanker (Mulyani, 2013).

Ada beberapa jenis kanker dan setiap kanker memerlukan pengobatan yang berbeda. Pada hampir semua jenis kanker, angka keberhasilan terapi sangat berkaitan dengan stadium saat diagnosa dan pengobatan. Semakin tinggi stadium saat di diagnosa, maka keberhasilan terapi akan semakin menurun dengan modalitas pengobatan yang semakin agresif. Karena itu, deteksi dini menjadi 
sangat penting artinya bagi penanganan penyakit kanker ini selanjutnya. Semakin dini kanker di temukan, semakin besar harapan kesembuhan (Kartikawati, 2013).

Breast Cancer Fondation Singapore memberikan data bahwa 1 dari 16 wanita di diagnosa menderita kanker payudara. Data tersebut menyebutkan bahwa dengan alasan yang belum bisa dipastikan, wanita etnis Cina di sana memiliki risiko lebih tinggi di bandingkan dengan etnis Melayu atau India, yaitu sekitar 1020\%. Kasus kanker payudara tertinggi terdapat pada kelompok umur 55-59 tahun (Savitri, 2015).

Jumlah penderita kanker payudara di Indonesia menempati urutan kedua setelah kanker leher rahim. Penderitanya pun ada yang baru berusia 18 tahun (Kartikawati, 2013). Berdasarkan data tersebut, para ahli kesehatan dan juga para penggiat Breast Cancer Awareness sangat menyarankan agar remaja putri melakukan pemeriksaan payudara sendiri, karena mereka yang paling mengenal struktur payudara normalnya. Jika ada benjolan atau perubahan tidak normal lainnya pada payudara, maka mudah untuk langsung menyadarinya. Pemeriksaan payudara sendiri yang rutin dilakukan satu kali setiap bulan dapat membantu penderita mendapatkan penanganan medis lebih awal. Pusat penelitian medis John Hopkins Research Centre di Amerika menyebutkan bahwa 40\% penderita kanker payudara berhasil sembuh karena kanker terdeteksi sejak dini melalui pemeriksaan sendiri di rumah secara teratur (Savitri, 2015).

Terjadi peningkatan kasus kanker leher rahim dan payudara yang tercatat di Dinas Kesehatan Provinsi Riau pada tahun 2019 sebanyak 471 kasus (Dinkes, 2019). Sebelumnya tahun 2016 di bulan Januari sampai bulan September, jumlah kanker payudara 350 kasus di mana terjadi pada wanita usia 15-24 tahun sebanyak 16 orang, wanita usia 25-44 tahun sebanyak 73 orang, wanita 45-64 tahun sebanyak 68 orang dan $65+$ tahun sebanyak 12 orang sedangkan pada tahun 2015 tercatat kasus kanker payudara di Pekanbaru sebanyak 177 kasus.

Melihat adanya kejadian kanker payudara pada usia remaja perlu tentunya pemahaman dan pelaksanaan deteksi dini kanker payudara dilakukan sedini mungkin, walaupun kasus kanker payudara yang terjadi pada remaja putri masih sedikit. Namun angka kejadian pada usia remaja dari Tahun 2015 ke Tahun 2016 
mengalami kenaikan dimana dari 4 orang menjadi 16 orang dan di usia remaja ini masih mengalami perkembangan dan pertumbuhan pada payudaranya.

Berdasarkan survei awal yang dilakukan pada remaja putri di SMAN 06, SMAN 10 dan SMAN 11 dengan pertanyaan yang sama di dapatkan dari SMAN 06 semua remaja putrinya mengetahui tentang kanker payudara, hanya 6 siswi yang mengetahui deteksi dini kanker payudara dan hanya 3 siswi yang melakukan deteksi dini. Begitu juga dengan SMAN 10 di dapatkan semua remaja putri mengetahui tentang kanker payudara, hanya 2 siswi yang tahu deteksi dini dan tidak ada yang melakukan deteksi dini kanker payudara. Dan terakhir SMAN 11, di dapatkan semua remaja putri juga mengetahui tentang kanker payudara, hanya 5 yang mengetahui deteksi dini dan 2 siswi yang melakukan deteksi dini kanker payudara. Dari ke tiga sekolah ini, siswi SMAN 10 yang paling rendah pengetahuannya tentang deteksi dini dan tidak melakukan deteksi dini.

Berdasarkan latar belakang tersebut, peneliti tertarik dan mengangkat masalah penelitian dengan judul : "Hubungan pengetahuan dengan tindakan terhadap deteksi dini kanker payudara pada remaja putri di SMAN10”.

\section{TUJUAN}

Penelitian ini bertujuan untuk mengetahui hubungan pengetahuan dengan tindakan terhadap deteksi dini kanker payudara.

\section{METODE}

Jenis penilitian yang digunakan pada penelitian ini adalah kuantitatif dengan menggunakan desain analitik dan rancangan cross sectional, dimana peneliti dalam penelitian ini melihat adakah hubungan pengetahuan dengan tindakan terhadap deteksi dini kanker payudara pada remaja putri di SMAN 10. Lokasi penelitian ini telah dilakukan di SMAN 10 Pekanbaru, pada bulan Maret sesuai izin yang diberikan pihak sekolah.

Populasi dalam penelitian ini adalah remaja putri kelas I dan 2 di SMAN10 Pekanbaru sebanyak 507 orang. Jumlah sampel dalam penelitian ini diambil secara Proportionate Stratified Random Sampling berjumlah 84 orang 
dengan kriteria inklui adalah siswa yang bersedia menjadi responden dan kriteria eksklusia adalah siswa yang berhalangan hadir.

Pengumpulan data dilakukan dengan mengisi lembar kuesioner terdiri dari 15 pertanyaan tentang pengetahuan mengenai SADARI dan 10 pertanyaan terkait melakukan tindakan SADARI. Variabel pengetahuan dikategorikan Baik, Cukup dan Kurang, dan variable Tindakan terbagi atas kategori Melakukan dan Tidak Melakukan. Pengolahan data dilakukan dengan analisis bivariat dengan uji $C h i$ Square

\section{HASIL}

Hasil uji bivariat dapat dilihat persentase responden yang tidak melakukan pemeriksaan deteksi dini kanker payudara lebih tinggi pada tingkat pengetahuan kurang $(85,72 \%)$ dibanding pengetahuan baik $(61,54 \%)$. Hasil uji statistik diperoleh $p$ Value yang diperoleh $>0,05$ berarti tidak ada hubungan antara pengetahuan remaja putri terhadap tindakan deteksi dini kanker payudara.

Tabel 1. Hubungan Pengetahuan Dengan Tindakan Terhadap Deteksi Dini Kanker Payudara Pada Remaja Putri Di SMAN 10 Pekanbaru Tahun 2017

\begin{tabular}{ccccccccc}
\hline Tingkatan & \multicolumn{3}{c}{ Tindakan Deteksi Dini } & & & $p$ \\
\cline { 2 - 5 } $\begin{array}{c}\text { pengetahuan } \\
\text { remaja putri }\end{array}$ & Melakukan & $\%$ & $\begin{array}{c}\text { Tidak } \\
\text { Melakukan }\end{array}$ & $\%$ & Total & $\%$ & $\begin{array}{c}p \\
\text { Value }\end{array}$ \\
\hline Baik & 5 & 38,5 & 8 & 61,5 & 13 & 100 & \\
Cukup & 8 & 16 & 42 & 84 & 50 & 100 & \multirow{2}{*}{0,150} \\
Kurang & 3 & 14,3 & 18 & 85,7 & 21 & 100 & \\
\hline Total & 16 & 19 & 68 & 81 & 84 & 100 & \\
\hline
\end{tabular}

\section{PEMBAHASAN}

\section{Pengetahuan Remaja Putri Terhadap Deteksi Dini Kanker Payudara}

Menurut (Notoatmodjo, 2014) pengetahuan adalah hasil dari tahu, ini terjadi setelah seseorang melakukan pengindraan terhadap suatu objek tertentu. Pengindraan melalui panca indra manusia adalah indra penglihatan, penciuman, pendengaran, rasa dan raba. Pengindraan yang baik akan meningkatkan pemahaman terhadap suatu objek atau informasi. Memahami diartikan sebagai suatu kemampuan untuk menjelaskan secara benar tentang objek yang diketahui dan dapat mengintepretasikan informasi tersebut secara benar. Maka dari itu 
meskipun responden pernah mendapat informasi tentang kanker payudara dan deteksi dini kanker payudara tetapi responden tersebut tidak melakukan penginderaan dengan baik, hal ini mengakibatkan pemahaman responden yang kurang baik (Nugraheni, 2010).

Dari hasil penelitian di SMAN 10 Pekanbaru menunjukkan sebagian besar memiliki tingkat pengetahuan yang cukup sebanyak $60 \%$ atau 50 orang. Hasil penelitian ini menunjukkan pengetahuan yang lebih baik pada remaja putri SMAN 10 diandingkan penelitian (Dewi, 2013) di Akademi Kebidanan Internasional Pekanbaru yang membahas gambaran perilaku remaja putri tentang pencegahan kanker payudara di SMAN 06 Pekanbaru Tahun 2013, dimana hasil penelitiannya diperoleh dari 80 responden memiliki pengetahuan yang rendah sebanyak $55 \%$ atau 44 orang.

Asumsi peneliti hal ini dikarenakan remaja putri di SMAN 10 Pekanbaru banyak mendapatkan informasi dari media sosial 47\% (24 orang) dan radio atau tv $31 \%$ (16 orang) yang informasinya tidak lengkap dibandingkan dengan informasi yang diberikan oleh tenaga kesehatan. Selain itu kesadaran/keinginan dari diri remaja putri yang kurang untuk mencari tahu informasi yang lebih banyak tentang deteksi dini kanker payudara. Kurangnya minat untuk mencari tahu disebabkan karena kurangnya pengetahuan tentang deteksi dini kanker payudara di lingkungan sekitarnya.

Namun demikian, hasil penelitian ini menunjukkan hasil pengetahuan remaja SMAN 10 Pekanbaru lebih rendah dibandingkan hasil penelitian yang dilakukan (Harnianti, 2016) tentang study periilaku SADARI pada nahasiswi Fakultas Kesehatan Masyarakat Universritas Halu Oleo yang menunjukkan 95,2\% pengetahuan baik

\section{Tindakan Remaja Putri Tentang Deteksi Dini Kanker Payudara}

Menurut Nugraheni (2010), SADARI merupakan salah satu cara yang lebih mudah dan efisien untuk dapat mendeteksi kelainan payudara diri sendiri. Pemeriksaan payudara sendiri (SADARI) adalah suatu prosedur untuk mengetahui kelainan-kelainan pada payudara dengan melakukan inspeksi secara berkala, misalnya sebelum melakukan pemeriksaan payudara terlebih dahulu harus 
mencuci tangan agar tidak terjadi infeksi pada payudara, serta penggantian bra merupakan salah satu dari penanggulangan untuk pencegahan infeksi pada payudara. Tujuan dilakukannya SADARI adalah untuk mendeteksi adanya kelainan-kelainan pada payudara baik struktur,bentuk ataupun tekstur (Pane, 2014).

Antara pengetahuan, sikap dan tindakan saling berkaitan, karena ketiga domain inilah yang akan membentuk perilaku seseorang. Pengetahuan atau kognitif merupakan domain yang sangat penting untuk terbentuknya tindakan seseorang (Notoatmodjo, 2014).

Dari hasil penelitian yang dilakukan di SMAN 10 Pekanbaru, sebagian besar remaja putri di SMAN 10 Pekanbaru tidak melakukan deteksi dini kanker payudara sebanyak $82 \%$ atau 69 orang. Hasil penelitian ini juga sesuai dengan (Dewi, 2013) di SMAN 06 Pekanbaru, dimana hasil penelitian diperoleh dari 80 responden tidak melakukan tindakan deteksi dini kanker payudara sebanyak $68,75 \%$ atau 55 orang. Begitu pula dengan hasil penelitian yang dilakukan (Harnianti, 2016) tentang study periilaku SADARI pada nahasiswi Fakultas Kesehatan Masyarakat Universritas Halu Oleo dengan pengetahuan yang baik 95,2\% namun melakukan tindakan sadari sebanyak 37.3\%.

Peneliti berpendapat dari hasil penelitian yang diperoleh di SMAN 10 Pekanbaru, diketahui tindakan remaja putri dipengaruhi pengetahuan dan sikap yang mereka miliki. Pengetahuan tentang deteksi dini kanker payudara pada remaja putri masih pada tingkat cukup dikarenakan informasi yang didapatkan tidak selengkap dengan informasi yang diberikan oleh tenaga kesehatan dan tidak pernah ada demonstrasi tentang deteksi dini kanker payudara di sekolah maupun di lingkungan sekitar.

\section{Hubungan Tingkat Pengetahuan Remaja Putri Terhadap Tindakan Deteksi Dini Kanker Payudara}

SADARI sebaiknya dlakukan secara rutin 1 kali per bulan setelah menstruasi selesai. Hal ini disebabkan pada fase ini, wanita dapat mengetahui kelainan yang tampak pada payudara secara langsung sebelum dilakukan 
pemeriksaan lebih lanjut lagi. Pemeriksaan payudara dapat dilakukan 5 hari -7 hari setelah menstruasi berakhir (Savitri, 2015).

Kesadaran akan pentingnya memahami apa dan bagaimana penyakit kanker payudara menjadi sangat penting supaya wanita mampu mendeteksi dini setiap gejalanya sehingga kanker tersebut bisa ditangani sejak dini. Jika kanker tersebut terdeteksi sejak dini, penanganannya pun efektif dan efisien sehingga tidak terlalu membahayakan dan bahkan bisa ditangani secara tuntas (Kartikawati, 2013). Pengetahuan dan kesadaran remaja putri terhadap pemeriksaan deteksi dini kanker payudara akan berdampak pada penurunan jumlah angka kejadian kanker payudara.

Hasil uji bivariat pada penelitian ini diperoleh tidak ada hubungan antara tingkat pengetahuan remaja putri terhadap tindakan deteksi dini kanker payudara.

Hasil penelitian ini bertolak belakang dengan (Rahmatika, 2015) yang menyatakan bahwa tingkat pengetahuan tentang kanker payudara yang tinggi akan berpengaruh terhadap tindakan SADARI. Tetapi ini sejalan dengan penelitian yang dilakukan oleh (Ambarwati, n.d., 2015) dengan judul hubungan pengetahuan SADARI dengan minat deteksi dini kanker payudara pada remaja puteri kelas XI di SMA N 1 Karangdowo Klaten, dengan hasil analisis data diperoleh tidak ada hubungan antara tingkat pengetahuan SADARI dengan minat deteksi dini kanker payudara.

Menurut asumsi peneliti tidak adanya hubungan tingkat pengetahuan terhadap tindakan deteksi dini kanker payudara, dilihat dari tingkat pengetahuan responden yang cukup 60\% (50 orang) tetapi tidak melakukan deteksi dini kanker payudara $82 \%$ (69 orang) hal ini, dapat terjadi disebabkan oleh faktor lain dimana tidak ada riwayat kanker payudara pada keluarga 89\% (75 orang) sehingga tidak menimbulkan kesadaran/keinginan untuk mendeteksi kanker payudara secara dini. Selain itu minat yang kurang terhadap pemeriksaan juga dipengaruhi oleh pengetahuan yang cukup tidak menjadikan remaja putri menganggap penting pemeriksaan deteksi dini kanker payudara. 


\section{KESIMPULAN DAN SARAN}

Dari hasil penelitian Hubungan Pengetahuan Dengan Tindakan Terhadap Deteksi Dini Kanker Payudara Pada Remaja Putri Di SMAN 10 Pekanbaru, dapat disimpulkan bahwa $60 \%$ atau 50 orang siswi memiliki pengetahuan cukup, hanya $18 \%$ atau 15 orang siswi yang melakukan tindakan deteksi dini kanker payudara dan tidak ada hubungan antara tingkat pengetahuan remaja putri dengan tindakan deteksi dini kanker payudara.

Perlu adanya sosialisasi dari tenaga kesehatan setempat bekerjasama dengan sekolah untuk memotifasi para remaja putri untuk melakukan SADARI sebagai deteksi awal kanker payudara.

\section{DAFTAR PUSTAKA}

Ambarwati, T. (n.d.). Hubungan Pengetahuan Sadari Dengan Minat Deteksi Dini Kanker Payudara Pada Remaja Puteri Kelas Xi Di Sma N 1 Karangdowo Klaten. http://jurnal.akbidmu.ac.id/index.php/jurnalmus/article/download/43/30.29 Maret 2017

Ambarwati, T. (2015). Hubungan Pengetahuan Sadari Dengan Minat DeteksiDini Kanker Payudara Pada Remaja Puteri Kelas Xi Di Sma N 1 Karangdowo Klaten. mu.ac.id/index.php/jurnalmus/article/download/43/30

Dewi, E. N. (2013). Gambaran Perilaku Remaja Putri Tentang Pencegahan Kanker Payudara di SMAN 06 Pekanbaru.

Dinkes. (2019). Profil Riau. https://dinkes.riau.go.id/sites/default/files/202012/Profil Kesehatan Provinsi Riau 2019.pdf

Harnianti. (2016). Study Perilaku SADARI Pada Nahasiswi Fakultas Kesehatan Masyarakat Hniversritas Halu Oleo. https://media.neliti.com/media/publications/185228-ID-studi-perilakupemeriksaan-payudara-send.pdf

Kartikawati, E. (2013). Awas Bahaya Kanker Payudara dan Kanker Serviks. Buku Baru.

Mulyani, N. S. (2013). Kanker Payudara dan PMS Pada Kehamilan. Nuha Medika

Notoatmodjo, S. (2014). Metodologi Penelitian Kesehatan. Rineka Cipta. 
Nugraheni, A. (2010). Hubungan Tingkat Pengetahuan Tentang Sadari Dengan Perilaku Sadari Sebagai Deteksi Dini Kanker Payudara Pada Mahasiswi Div Kebidanan Fk Un. https://digilib.uns.ac.id/dokumen/download/15188/MzAwOTU=/Hubunga n-tingkat-pengetahuan-tentang-sadari-dengan-perilaku-sadari-sebagaideteksi-dini-kanker-payudara-pada-mahasiswi-D-IV-Kebidanan-FK-UNSabstrak.pdf

Pane, M. S. R. (2014). Gambaran Pengetahuan, Sikap dan Tindakan pada remaja putri terhadap deteksi dini kanker payudara di SMA Budi Murni 1 Katolik Medan. http://jurnal.usu.ac.id/index.php/kpkb/article/download/10241/481

Primadi, O. (2016). Situasi Penyakit Kanker. http://www.depkes.go.id/download.php?file=download/pusdatin/buletin/b uletin-kanker.pdf

Rahmatika, R. (2015). Hubungan Pengetahuan Tentang Kanker Payudara Dengan Tindakan SADARI Pada Mahasiswa Semester II DIV Kebidanan Di STIKES 'Aisyah Yogyakarta. http://repository.usu.ac.id/bitstream/123456789/52137/4/Chapter II.pdf.

Savitri, A. (2015). Kupas Tuntas Kanker Payudara, Leher Rahim, Dan Rahim. Pustaka Baru. 